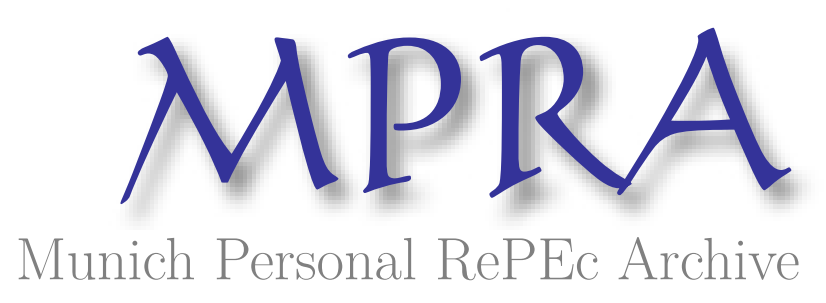

\title{
The Effects of School Quality on Long-Term Health
}

Sansani, Shahar

College of Management, Israel

August 2009

Online at https://mpra.ub.uni-muenchen.de/22189/

MPRA Paper No. 22189, posted 19 Apr 2010 17:56 UTC 


\title{
The Effects of School Quality on Long-Term Health ${ }^{1}$
}

\author{
Shahar Sansani ${ }^{2}$
}

August, 2009

\begin{abstract}
In this paper I estimate the relationship between school quality and mortality. Although many studies have linked the quantity of education to health outcomes, the effect of school quality on health has yet to be examined. I construct synthetic birth cohorts and relate the quality of education they attained to their mortality rates. I find that there is a statistically significant relationship between the mortality-schooling gradients, which depict the return to a year of schooling, and the length of school term and relative teacher wage. For instance, increasing the relative teacher wage by one standard deviation results in about 1.9 less deaths per 1,000 people per extra year of education. My results suggest that one way to improve the health of the population is to improve school quality.
\end{abstract}

JEL codes: I12, I21

Keywords: quality of education, health production

\footnotetext{
${ }^{1}$ This paper was originally part of my dissertation "Compulsory Schooling Laws, School Quality, and the Impact on Health Outcomes" (August, 2009).

${ }^{2}$ Department of Economics, College of Management, Rishon Lezion, Israel, 75490; sansanis@ colman.ac.il. I am indebted to my dissertation chair Doug Miller for his help with this paper. I also thank Peter Lindert, Marianne Page, Alan Barreca, Tohm Sansani, and participants at the UC-Davis applied micro brownbag series for their helpful comments.
} 


\section{Introduction}

This paper examines the relationship between school quality and death rates. The outcome of this relationship has important implications for devising optimal education and health policy. In addition, my work complements the growing literature on the effects of education quantity (years of schooling) on health outcomes. My research design is similar to studies that examine the pecuniary returns of school quality, except that mortality rates are my outcome of interest. Specifically, using Census data, I construct mortality-schooling gradients by state and decade for cohorts who attended school between 1918 and 1958. I then examine to what extent the variation in the health return to a year of education can be explained by changes in school quality. The health return to education is depicted by the slope of the mortality-schooling gradient. The key quality measures in my study are pupil-teacher ratios, the length of the school year, and the relative teacher wage. I obtain this data from various editions of the Biennial Survey of Education.

Understanding the role that education policy can have in influencing the public's decisions and actions regarding their health is important for improving disparities in long-term health outcomes of children with different socio-economic backgrounds ${ }^{3}$. And, in general, improving health is especially important in light of the increased spending on healthcare, which as the percentage of GDP has increased from 5.2 percent in 1960 to 16.2 percent in $2008^{4}$.

In simple terms, education policy makers interested in improving the long-term wellbeing of students have two mutually inclusive tools at their disposal: improving school quantity (e.g., graduation rates), and/or improving school quality (e.g., length of school term). While a

\footnotetext{
${ }^{3}$ For example, in 2006 the age-adjusted death rates for blacks was 10.2 while for whites it was 7.9 (Heron, Hoyert, $\mathrm{Xu}, \mathrm{Scott}, \&$ Tejada-Vera, 2008).

${ }^{4}$ US Department of Health and Human Services.
} 
variety of studies have established the relationship between education quantity and health ${ }^{5}$, the role that education quality plays in health has been overlooked ${ }^{6}$. Those quantity-health studies that do exist show a positive and significant relationship between the two that is independent of income and access to health insurance ${ }^{7}$. It is not the case that these other measures do not matter for health outcomes, but rather that the one variable that is consistently and strongly a predictor of better health is more years of education. This would suggest to policy makers, for example, that increasing the percent of students that graduate high school is an effective tool for promoting long-term health ${ }^{8}$.

However, the positive school quantity-health relationship reveals little about the importance of school quality. In some cases, policy makers may have more readily available tools for improving school quality, such as reducing class sizes. As such, by empirically estimating the effects of school quality on mortality my work has important implications for education policy 9 .

The key measures of school quality in my study include pupil-teacher ratios, length of school terms, and relative teacher wages. I examine the role of each of these three quality measures in order to offer more practical policy recommendations. For example, close to half of

\footnotetext{
${ }^{5}$ Silles (2009), Lleras-Muney (2005), Smith (2004), and Mazumder (2008) are some examples.

${ }^{6}$ In varying degrees education quality has been shown to have an effect on non-health returns to education. See Card and Krueger (1992), Hanushek (1996), Dustmann, Rajah, \& van Soest (2003), Bedard (2003).

${ }^{7}$ Income and the resources that it generates access to (e.g. health insurance) has recurrently been posited as the real reason for the observed differences in health outcomes across education groups. Smith (2004) finds that in all the cases he examines except cancer, education is more strongly related than income or wealth to the onset of major as well as minor diseases. Income and health insurance were also mentioned as illustrating only part of the story in a recent survey of experts studying the education-health relationship (Kolata, 2007).

${ }^{8}$ Stacey (1998) notes that education externalities such as improvements in family formation patterns and the environment, as well as a decrease in crime, would accompany the direct effects of improved health from more years of education. As such, if education quality is an important part of the education process, then improving it would add to the benefits of increase quantities of education mentioned above.

${ }^{9}$ Note that improving school quality may also have the benefit of increasing school quantity.
} 
the variation in expenditure-per-pupil across school districts is due to class size differences ${ }^{10}$. By exploring whether the pupil teacher ratio is significantly related to health, I determine whether this focus is justified. Moreover, some school districts have recently implemented extended school days and school terms. If there is a significant relationship between the length of the school year and health, this could have unforeseen positive impacts on health ${ }^{11},{ }^{12}$.

To determine this relationship between school quality and health, I exploit cross-state differences in the trends of school quality over time. While school quality and health have both improved over time in the United States, there are vast differences in trends across states. Death rates have decreased drastically over time, but still range from a high of 10.14 deaths per 1,000 people in Mississippi to a low of 7.13 deaths per 1,000 people in Minnesota ${ }^{13}$. In addition to the mortality disparities across both states and education levels, there are disparate differences in school quality throughout the first half of the $20^{\text {th }}$ century (the period examined in this study). For example, for an individual born between 1912 and 1921 the pupil-teacher ratio would have varied from an average of 37.1 in Arkansas to an average of 18.0 in Wyoming for the years they obtained their primary and secondary education ${ }^{14}$. Moreover, as is the case with death rates, there was a reduction of this cross-state variation over time. Figures 1, 2, and 3 show the convergence of the three quality measures used between 1918 and 1958 for a high-quality education state (New York) and a representative low-quality education state (Arkansas) ${ }^{15}$.

\footnotetext{
${ }^{10}$ Card and Krueger (1998)

${ }^{11}$ Zuckerbrod and Trujillo (2007)

${ }^{12}$ Data-permitting, studying the impacts of these policies is an avenue of future research.

${ }^{13}$ Hawaii has the lowest age-adjusted death rate with 6.49 deaths per 1,000, but it is excluded from this analysis (along with Alaska) since it was not part of the US until 1959.

${ }^{14}$ Relative teacher wage (as a ratio to average earnings for state workers in that state) varied from a high of 2.19 in Washington, DC to a low of .79 in Mississippi for that same cohort. For the last main measure of school quality used, term length, the high and low were 184.8 and 139.5 in New York and Mississippi, respectively.

${ }^{15}$ Arkansas could be substituted with other Deep South states that also had very low school quality, while New York is one of the higher school quality states overall.
} 
While there are other potential variables I can use to measure health, I use mortality to quantify health for several reasons. First, mortality does not have the problem of measurement error that occurs with self-reporting of certain health variables (e.g. functional limitations) that are used in some of the education-health literature. Second, measuring the severity of health outcomes can be difficult, unlike mortality which is clearly defined ${ }^{16}$. Third, as health conditions decrease, the risks of mortality increase, so mortality encompasses the worst case scenario for all of them and is an important outcome in itself ${ }^{17}$. Finally, since mortality usually occurs well after the completion of one's education, concerns of reverse-causality are mitigated. I expand on this potential reverse-causality issue in a later section ${ }^{18}$.

I use two approaches to quantify the relationship between school quality and mortality. First, using ordinary least squares, I estimate the direct relationship between quality of education and health by employing a model with death rates as the dependent variable and the three school quality measures as explanatory variables, controlling for state, cohort, and census-pair fixed effects. With this specification, my parameter estimates are identified from changes in quality over time for a particular state, cohort, and census pair. I find that the pupil-teacher ratio and length of school term are strong predictors of death rates, with the magnitude varying depending on the specification used.

In the second part of the analysis, I follow a similar methodology to that used by Card and Krueger (1992) ${ }^{19}$. Because I do not have individual data on deaths, I calculate death rates by education category (e.g., high school graduates) and estimate the mortality-school quantity

\footnotetext{
${ }^{16}$ Some studies ask respondents to rank how they are feeling, which can be difficult to compare across people.

${ }^{17}$ From a health expenditure aspect, it may be more fitting to study those ailments that are expensive to treat. This is a promising venue for future research.

18 There are also disadvantages of looking at mortality as well. Primary among these is that quality of life may be lower as people get older, so that an extra year of life is not the same at 70 as it is at 80 .

${ }^{19}$ They examine how the quality of education affects the return to a year of education in terms of earnings.
} 
gradient for a particular state of birth, cohort, and census pair. Then, I examine whether school quality can explain the differences in the mortality-schooling gradients.

I find that the length of school term and relative teacher wage are the most significant predictors of the mortality-schooling gradient. That is, increasing either the length of school term or relative teacher wage makes the return to a year of schooling (in terms of decreased mortality) greater. For example, numerous studies have shown that people with 12 years of education have lower death rates than those with 10 years of education. What my findings imply is that if we look at a group with ten years of education and another group with 12 years of education each in two different states, the difference in death rates between the two groups would be greater in the state with the higher quality of education. In other words, in the state where there is higher quality education, there is more of a health benefit to attending school longer. Thus, increasing school quality is an additional avenue through which health disparities across SES groups can be decreased, as it augments the positive effect of increased education quantity on health.

\section{What is the Relationship Between Education and Health?}

Previous studies that have focused on the quantity of schooling have concluded that school quantity matters: more schooling means better health. However, the point of contention is whether the education-health relationship is a causal one, and if so, in what direction. The most often used direction of causality is "education causing health", which is assumed in my specifications $^{20}, 21$.

\footnotetext{
${ }^{20}$ See Lleras-Muney and Cutler (2008) for a detailed explanation
} 


\subsection{Causal Impacts}

Several papers try to pinpoint the causal relationship between education and health by utilizing compulsory schooling laws as instruments for education using both US and non-US data. Lleras-Muney (2005) finds that using weighted least squares, a one year increase in education decreases the death rate by 3.6 percentage points, while with IV estimates this number jumps to $6.3^{22}, 23$. This was the first paper to use a quasi-experimental approach to ascertain the effects of education quantity on health ${ }^{24}, 25$.

\subsection{Mechanism}

Other papers have aimed to identify the mechanism through which education and health are related. That is, if education is a crucial determinant in health then why is it so? The common theme among these papers is that the more educated are more likely to 1) adhere to more complicated health treatments, 2) understand the treatments, 3) trust that these treatments will work in the first place, and 4) be able to foresee the health benefits that following the treatments today will have later in life.

\footnotetext{
${ }^{21}$ This positive correlation between education and health being induced by an unobservable third factor is also a possibility. That said, papers such as Fuchs (1982) and Barsky, Juster, Kimball, \& Shapiro (1997) addressing this hypothesis still leave room for other factors, of which education is one.

${ }_{22}$ The actual estimates that appear in Lleras-Muney (2005) are -0.017 and -0.051 , respectively. The estimates above are her updated results after correcting for a programming error in the original paper (Lleras-Muney, 2006).

${ }^{23}$ Using slightly different census samples, Mazumder (2008) shows that Lleras-Muney's results are not robust to the inclusion of state specific time trends, which he cites could point to the instruments she uses picking up cohort trends rather than their intended purpose of solely picking up the effects of the laws.

${ }^{24}$ See Silles (2009), Oreopoulos (2007), Arendt (2005), and Grabner (2006) for other papers using changes in schooling laws as instruments for education when examining the education-health relationship.

${ }^{25}$ In one of the first non-quasi-experimental papers to study the relationship, Berger and Leigh (1989) apply an instrument for family ancestry and examine the effect of schooling on both blood pressure and measures of functional limitations and work disability. They find strong effects of schooling and predicted schooling on blood pressure of approximately -0.5 and -0.2 for each year of education for systolic and diastolic blood pressure, respectively.
} 
Goldman and Lakdawalla (2001) find that health disparities across education groups are greater when they involve ailments that require a lot of treatment. This suggests that more educated individuals are more likely to stick to complex and time-intensive treatment programs. Goldman and Smith (2002) investigate how individuals comply with complicated health treatments for ailments such as HIV and insulin dependent diabetes. They find a 20\% point difference in adherence to HIV treatment and a $25 \%$ point difference in staying on the same diabetes treatment for college graduates relative to high school dropouts ${ }^{26},{ }^{27}$. Lleras-Muney and Lichtenberg (2002) find that the more educated are more likely to use new drugs approved by the FDA, even after controlling for insurance status and income.

Overall, these latter papers demonstrate that there is some causal relationship between education and health ${ }^{28}$. However, they only examine the effects of the quantity of education on health, but not the quality. On the assumption that each year of education differs in quality, these studies are missing part of the picture. This paper fills that gap by incorporating educational quality differences in explaining the link between education and health.

\section{Does School Quality Matter?}

The relationship between school quality and non-health outcomes such as earnings and test scores has also been studied extensively. The paper whose methodology I most closely

\footnotetext{
${ }^{26}$ On the contrary, Goldman and Smith (2005) find that the more educated are not more likely to adopt new medical technologies related to hypertension.

${ }^{27}$ Another paper that uses diabetes as the health outcome is Smith (2007). He finds that lower education attainment groups are more impacted by diabetes because they 1) are more likely to have the disease in the first place, 2) are at a greater risk of not having it diagnosed, and 3) once it is diagnosed, they are less likely to stick to the complicated treatments.

${ }^{28}$ In addition to the reasons noted above, Ross and Wu (1995) mention that the more educated have a greater "sense of control" and "social support" that may help keep health from deteriorating.
} 
follow is Card and Krueger (1992) ${ }^{29}$. They estimate a standard returns to education equation, but obtain a state of birth and cohort-specific return to education that is independent of the region of residence, thus controlling for factors that can make the return to a year of schooling different in one region of the country than another. They find that pupil-teacher ratios and relative teacher wages are strong predictors of these different returns to education.

Examining the emphasis on high-quality education from a different angle, Black (1999) adds to widespread anecdotal evidence by showing that parents are willing to pay for their children to go to better schools. Although it has been empirically difficult to prove, parents' willingness to pay more for higher quality education shows its perceived importance. Examining house prices in Massachusetts, she finds that parents are willing to pay 2.1 percent more for housing where schools have test scores that are 5 percent higher.

There have been other papers that inspect the relationship between school quality and other outcomes besides earnings. Reviewing the studies that examine test scores, for example, could give some insight into how to measure the school quality and health relationship ${ }^{30}$.

Overall, most studies find that increases in school quality lead to better test scores, although some of these studies find no effect.

A common theme in most previous work is that the focus is only on specific grades, or on a few grades at the elementary level. It could be that the effects of school quality are not constant across grades, or that they are particularly important at some grades more than others.

\footnotetext{
${ }^{29}$ See also Bedard (2003) and Dustmann et al. (2003). Both papers use a methodology similar to Card and Krueger (1992), with Bedard using Canadian data, and Dustmann et al. using data from England and Wales. But unlike Card and Krueger, both disaggregate the data into different portions of the wage distribution.

${ }^{30}$ See Krueger (1999) who uses random assignment of students to different class sizes, Angrist and Lavy (1999) who use a regression discontinuity design, and Hoxby (2000) who uses the random timing of births, for the effects of nearly exogenous variations in class size on test scores. Pritchett and Filmer (1999) summarize a few studies in developing countries that look at factors other than class size, and find that the availability of learning supplies including books and desks also influences outcomes.
} 
My work encompasses all grades so I am able to ascertain the effects of school quality on health no matter in which grade(s) the effect of school quality on health is most important.

\section{Methodology}

\subsection{Direct Relationship}

I divide the analysis into two stages. In the first stage, I simply look at OLS estimates of the relationship between school quality and death rates, with and without controlling for years of schooling and several other covariates. This estimates the direct relationship between changes in school quality within a particular state for a specific birth cohort to changes in that cohorts' death rates.

Under the assumption that changes in school quality are not correlated with omitted variables correlated with changes in death rates, these regressions estimate the causal effect of school quality on death rates. For example, attitudes about investment in the human and health capital of children may be an important omitted variable. It is conceivable that in certain states increased attention was given to the well-being of children. This increased attention would raise both child health and school quality. The improvement in child health could improve long-term health, thereby causing a positive correlation between school quality and long-term health, a relationship that is not causal. In this context, such change in attitudes could be what led to better health outcomes (and greater returns to years of education), and not the improvements in school quality. In the sense that rising school quality may not be completely exogenous, the estimations of the direct relationship between school quality and death rates should be interpreted with some caution. 
In addition to the possibility of omitted variables, the methods I use are subject to the same concerns that are associated in general with most school quality work and the work of Card and Krueger (1992) in particular. In particular, I use three factors to measure school quality: 1) pupil-teacher ratio, 2) length of school term, and 3) relative teacher wage. However, these are only a small part of the whole education process. Explicit measures of innate ability are not available, nor are measures of non-school inputs, such as family background ${ }^{31}$. However, using state averages minimizes the unobserved effect of a variable like family background. For this type of measure I expect there to be less variation across states than between individuals within a state.

To establish this direct relationship, I estimate models of the following form:

$D_{c j t}=\delta_{c}+\eta_{j}+\psi_{t}+\beta_{1}$ PupTeach $_{c j}+\beta_{2}$ Length $_{c j}+\beta_{3}$ RelWage $_{c j}+\rho E_{c j t}+\phi X_{c j t}+\varepsilon_{c j t}$

Where the $\delta$ are cohort fixed effects, the $\eta$ are state of birth fixed effects, and the $\psi$ are census-pair fixed effects. c, j, and t designate cohort, state of birth, and census pair, respectively. $E$ represents years of schooling (which is included in some specifications), and the $X s$ are different combinations of average income, metropolitan status, and average age. The regressions are weighted by the population per state at the earlier census year in the census pair.

\subsection{Mortality-Schooling Gradient}

The second set of regressions more closely resembles the methodology used by Card and Krueger (1992), as I am able to estimate state-specific returns to education, but in terms of health (death rates) rather than earnings. I then estimate the impact of school quality on their health returns to education.

\footnotetext{
${ }^{31}$ Hanushek (1996)
} 
This second analysis is split into two steps. In the first step, I divide the observations into four different education groups by cohorts' birth year and state of birth for the four different censuses examined. The birth cohorts are 1912-1921, 1922-1931, and 1932-1941 while the four education attainment groups are zero to eight years, nine to 11 years, 12 years, and 13 years and over. For each of these education groups, I take the average education and also calculate the death rates, resulting in four different education-death rate combinations for 441 state-of-birth, cohort, and census-pair combinations. For example, I divide the cohort born in Georgia between 1912 and 1921 into four education groups for each census pair. For each of these education groups I calculate the average years of education attained and death rates.

From these four observations per state-of-birth, cohort, and census-pair combinations, I estimate 441 equations of the following form:

$D_{\text {jcte }}=\beta_{\text {jct }} E_{\text {jcte }}+\varepsilon_{\text {jcte }}$

The $\beta$ s from this equation provide 441 mortality-schooling gradients, each based on four observations. For instance, a $\beta$ of -4.16 based on the 1912-1921 cohort born in Georgia using the 1980-1990 census pair implies a 4.16 percentage point drop in the death rate for each extra year of education. Figure 4 shows graphically how I calculate each of these gradients.

I then regress these $\beta$ s on the quality variables to see how well school quality is explaining these variations in the mortality-schooling gradient:

$\beta_{c j t}=\alpha_{j}+\psi_{t}+\gamma_{c}+\phi Q_{c j}+\varepsilon_{c j t}$

I include state fixed effects, cohort fixed effects, and census-pair fixed effects to isolate the impact of school quality on the education gradient. If states with improving school quality also have improving hospitals, the superior hospitals may be the reason for better health later in life and not the quality of schooling. The inclusion of the fixed effects reduces the possibility of 
erroneously attributing the positive health impacts to school quality. To reduce this possibility even further, some specifications include census pair times state fixed effects as well as census pair times cohort fixed effects ${ }^{32}$.

I run equation (3) for the full sample of 49 states, but also for a restricted sample of 33 states that have at least 20,000 observations per state-of-birth, cohort, and census pair. I explain the reasoning for the use of cells with a large number of observations in a later section.

I include average state income for the years each cohort attended school in some of the specifications. An increase in resources available in a state could drive the relationship between a year of education and death rates, so having a proxy for these resources (i.e. average income) helps isolate the relationship between changes in school quality and death rates.

The health returns to education are assumed to be linear. Heckman, Farrar, and Todd (1996) point out that if the relationship is assumed to be linear in studies that examine the returns to education in terms earnings, it can lead to different conclusions about the quality-earnings relationship. This is not a top concern in this analysis, as their main criticism is the omission of allowing for sheepskin effects, which should not impact health outcomes ${ }^{33}$. A separate potential concern relates to the choice of the number of education categories used to estimate the mortality-schooling gradient. In setting the number of education categories, the goals are 1) having categories with a large number of observations to minimize sampling error, 2) choosing category boundaries that are less prone to people jumping categories between censuses, and 3) having enough categories so that a mortality-schooling gradient can be estimated. I report results for specifications with different education categories in the appendix. In general, my results are

\footnotetext{
${ }^{32}$ Recall that Mazumder (2008) finds that the main results of Lleras-Muney (2005) are not robust to the inclusion of stricter right hand side controls.

${ }^{33}$ That said, if the relationship between educational quality and health outcomes operates indirectly through income, sheepskin effects may indeed be salient.
} 
similar when I use alternate ways to generate the mortality-schooling gradient. I believe the four education categories I choose do the best job of balancing the three concerns.

\section{Data}

I extract state-specific school quality data from 1918 to 1958 from various editions of the Biennial Survey of Education. Among the wide array of education data in those volumes is data on the three main school quality variables that I use: term length, pupil-teacher ratios, and teacher salaries. I input variables like the length of term and pupil-teacher ratios as is, while I divide the salaries by the public salaries paid in that state ${ }^{34}, 35$. The other two schooling variables I use are average pupils per school and the percent of schools that are "one-room" schools. I then average these variables by state over the years an individual born in that state would have attended school. For example, I assign the cohort born in 1912 in Georgia the average of the school quality variables in Georgia from 1918 to $1930^{36}$. Restricting the data to whites minimizes the unobserved factors that could be influencing the mortality-schooling gradient differently by race ${ }^{37}$. Since I measure the school quality inputs from 1918 to 1958 , the youngest individuals are 29 years old in the 1970 census, and the oldest individuals are 88 years old in the 2000 census.

\footnotetext{
${ }^{34}$ Following Card and Krueger (1992), for 1918-1938 the denominator is the wage paid to laborers on federal road construction projects, while for 1940-1956 the average state-level wage of workers covered by the social security system is used.

${ }^{35}$ I normalize by the salary in a state since cost-of-living, and therefore overall salaries, varied greatly from state to state. That is, I do not want to treat a teacher salary improving by $\$ 100$ in New York the same as if that improvement were in Mississippi.

${ }^{36}$ The data on quality is only available for even years. As a result, the quality measures for each even year are also assigned to the previous odd year.

${ }^{37}$ In addition to these unobserved factors, school quality measures were drastically different between the schools in the South that were segregated during this time period.
} 
I calculate death rates from the 1970, 1980, 1990, and 2000 censuses via the Integrated Public Use Microdata Series (IPUMS) using a counting method used by Lleras-Muney (2005). For example, I obtain the 1980-1990 death rates by subtracting the number of people in a particular state-of-birth/cohort in 1990 from the number of people in that state-of-birth/cohort in 1980, and dividing by the 1980 count $^{38}$.

Since the dependent variable is only available by state of birth and cohort, I average the independent variables over states of birth and cohorts as well. For example, when education appears as an independent variable, it refers to the average years of education for individuals from a particular state of birth and cohort for that census year. Also, I measure these variables at the earlier census of a census pair. That is, I match the 1970-1980 census pair death rate with 1970 education, since matching to 1980 education levels would include only the average education of those people that survived to 1980 .

There are two measures of income. Income earned while the cohorts attended school is one measure, which I obtain from various editions of the Statistical Abstract of the United States. I divide total tax return income by the number of returns and then convert these to real terms ${ }^{39}$. I use the latter income measure in the mortality-schooling gradient analysis. The other set of income variables is simply the average income for a specific cohort-state of birth using the 1970, 1980, and 1990 censuses, which I use to get an indicator of "resources" in some of the specifications where I examine the direct relationship between school quality and death rates.

\footnotetext{
${ }^{38}$ There are two 1970 nationally representative 1 in 100 state samples that are combined and multiplied by 50 . The 1980 data is a nationally representative 1 in 20 sample so the count of people in a particular state of birth-cohort cell is obtained by multiplying by 20 . The 1990 and 2000 data are weighted samples, so each state of birth-cohort count is multiplied by the average number of people represented by each observation of that state of birth-cohort.

${ }^{39}$ The 1915 to 1939 data is from a file constructed by Lleras-Muney and 1940 to 1958 is obtained from the Statistical Abstracts using the method above.
} 


\section{Results}

The summary statistics in Table 1 depict how school quality, death rates, and the education gradients change for successive cohorts. Over time (i.e., for younger cohorts), the pupil-teacher ratio and length of school term improve, while the relative teacher wage is virtually constant. Portraying the raw education-health relationship, death rates are lower for the more educated groups. Moreover, in general the education gradients are steeper for later cohorts, implying a greater health return to a year of schooling, and the possibility that improving school quality is accountable for this.

\subsection{Direct Relationship}

I divide the results of the first methodology, which establishes the direct relationship between school quality and death rates, into two main categories. One set of results includes the regressions of death rates on school quality only, and the other set includes quality as well as the number of years of education as independent variables.

Figures 5, 6, and 7 depict graphs of the relationship between death rates and the three school quality variables without controlling for any covariates and weighting by state population. As expected, better quality of education is associated with lower death rates ${ }^{40}$.

Table 2 presents the results of the specification that only consists of the quality variables as the main independent variables. When I include the quality variables with just state-of-birth, cohort, and census-pair fixed effects, the pupil-teacher ratio and length of school term are significant, while the relative teacher wage is not (and has an unexpected positive sign). When I

\footnotetext{
${ }^{40}$ What constitutes better quality is presumed from 1) longer school terms giving more time for material to be covered, 2) lower pupil teacher ratios meaning more attention per student, and 3) higher relative teacher wages attracting better teachers.
} 
include all three variables simultaneously, the pupil-teacher ratio estimate gets nosier, the length of school term is significant, while the relative teacher wage is significant, but with the unexpected positive sign. The results change little when I include covariates for average income, percent in metro areas, and average age. The magnitudes of these coefficients are consequential as well. The 0.33 coefficient on the pupil-teacher ratio implies that a one standard deviation (equal to 4.47) improvement in it is associated with a decrease of 1.48 percentage points in the death rate. Moreover, the -0.12 (in one of the specifications) coefficient on length of school term implies that a one standard deviation (10.4 days per year) improvement in that input is associated with a decrease of 1.25 percentage points in the death rate.

I include both education quality and quantity variables in the specifications in Table 3. Including education quantity takes some of the explanatory power away from the quality variables. However, the length of school term is still significant in most of the specifications. Moreover the magnitudes are roughly the same as when I put only the quality variables as independent variables. The education quantity variable is imprecisely measured, although given that these are state averages of years of education, this result is somewhat anticipated as there is not much across-cohort and state-of-birth variation in this variable.

\subsection{Mortality-Schooling Gradient}

The main results of the second methodology, where the quality variables predict the mortality-schooling gradient, are in Table 4. I also run this specification dropping state censuspair cohort combinations with less than 20,000 people ("restricted sample"), since states with a small number of observations are more suspect to sampling error. The results using the full sample show that improving school quality leads to greater health returns to a year of schooling 
when the quality variables are included separately in each equation. The relative teacher wage is statistically significant in these models, but the pupil-teacher ratio and length of school term are not significantly estimated. When I include all three variables simultaneously, some of their precision is reduced because of the high collinearity among them. The length of term and pupilteacher ratio are still not precisely estimated, while the relative teacher wage is still significant at the $1 \%$ level.

The results are more precise in the specifications where I restrict the sample to only include states with a certain number of observations ${ }^{41}$. The main changes are that the pupilteacher ratio and length of school term are now significant on their own, although neither variable is significant when I include all three variables simultaneously.

In the regressions (Table 5) with the interacted state times census-pair fixed effects and cohort times census-pair fixed effects, the results, although less precisely estimated, are similar in regard to the point estimates and their sign. In particular, the main difference is that the precision of the estimates shifts to some degree from the relative teacher-wage variables to the pupil-teacher ratio variables.

The magnitudes of the coefficients are meaningfully large in the models where I estimate the mortality-schooling gradient, as they were in the models estimating the direct relationship. The coefficient of -0.011 on the length of term in the restricted sample implies that an increase of ten days (where the standard deviation of the length of school term is 10.4 days) is related to a 0.11 percentage point decrease in the death rate (or 1.1 deaths per 1,000 people) for an extra year of education. The coefficient of -0.772 on the relative teacher wage in the unrestricted sample implies that an increase of 10 percentage points in the relative teacher wage (where the standard

\footnotetext{
${ }^{41}$ In fact, just dropping Washington, DC from the full sample helps the precision of the estimates.
} 
deviation is $28 \%$ ) is related to a 0.077 percentage point decrease in the death rate (or .77 deaths per 1,000 people) per extra year of education. To put these numbers in context, the overall ageadjusted death rate in the US is about 8.45 people per $1,000^{42}$.

The results in Table 4 are similar, though less precise, to those found by Card and Krueger (1992). They find that 1) individually the quality variables significantly predict the state-specific earnings returns to education, and 2) the quality variables lose some of their explanatory power when included concurrently. However, the relative magnitudes of their coefficients are much smaller than mine. For example, their largest coefficient on the pupilteacher ratio indicates that to get a merely 0.1 percent increase in the weekly wage, the pupil teacher ratio would have to decrease by 14 .

Even though the magnitudes of the relationship I find between school quality and mortality are quite large as is, any sign of a link between the two most likely underestimates the true relationship. There has been some selection on surviving to a certain age since I calculate death rates for people beginning with the youngest cohort of those between the ages of 29 and 38 in 1970. In other words, people with low levels of school quality that died before their $29^{\text {th }}$ birthday are not included in the analysis.

While the main specification includes the core quality variables, I also run the analysis with a more comprehensive set of quality variables by including measures for the number of oneroom schools and the average number of students per school in that state. The result for this specification is in Table 6. The results on the original three variables (pupil-teacher ratio, length of school term, and relative teacher wage) are put in for comparative purposes, but are obviously of the same magnitude as in Table 4. The coefficient on the average number of students per

\footnotetext{
${ }^{42}$ Miniño, Anderson, Fingerhut, Boudreault, \& Warner, (2006).
} 
school is significantly estimated in the regression with the restricted sample with a positive sign, indicating that schools with more students are associated with lower returns to a year of schooling ${ }^{43}$. Similarly, the percent of one-room schools has a negative sign, indicating that states with more one-room schools have greater returns. Over time, the number (percent) of one-room schools is decreasing while the average number of students per school is increasing. Therefore, these results show that students in states that go "against" this trend have greater returns to a year of schooling.

In columns 6 and 12 I put in all the variables for the unrestricted and restricted sample, respectively. In the unrestricted sample the relative teacher wage and percent of one-room schools are still significant predictors of the gradient, while with the restricted sample, only the average number of students per school is still significant. This result suggests that even accounting for the pupil-teacher ratio, as there are more students per school there are less resources per student, and this causes the returns to schooling to decrease. As with the models with only the main three quality variables, the results get smaller in magnitude and less precise when cohort times census-pair fixed effects and state times census-pair fixed effects are included $^{44}$.

\section{Specification Issues}

There are several issues with the data and methodology that need to be addressed. The counting method I use to calculate death rates results in some being either negative or extraordinarily large. The negative death rates occur when there are more observations in the later census for a state-of-birth/cohort than in the earlier one. However, Lleras-Muney (2005)

\footnotetext{
${ }^{43}$ Recall that the mortality-schooling gradient is negative, so a positive coefficient indicates a flatter gradient.

${ }^{44}$ Results available upon request
} 
notes that death rates calculated in this fashion are on average similar to those using individual data from the National Health and Nutrition Examination Survey I Epidemiologic Follow-up Study, 1992. Also, I minimize this potential problem by weighting by state population since these outlying death rates are more common among states with smaller populations ${ }^{45}$. Moreover, restricting the sample to states with large populations only strengthens the results, indicating that the large effects found with the unrestricted sample occur despite these small population states and not because of them ${ }^{46}$.

There are also some positive mortality-schooling gradients because the gradients are only measured over four observations and the sampling error mentioned above ${ }^{47}$. This is not a major concern, however, since 1) there are relatively few positive gradients, 2) the gradients are generally normally distributed, and 3) the estimations are based on 441 gradients.

As previously mentioned, I assume in this paper that the causal effect is from education to health. Numerous papers have studied the exact opposite relationship by examining how health affects SES outcomes both in the short term and in the long run. Black, Devereux, \& Salvanes (2007) use within-twin variation in birthweight to examine the effects on short-run and long-run outcomes, finding a significant effect on outcomes such as earnings and education, among others ${ }^{48}$. I do not suspect that this reverse-causality issue is a problem in my analysis since I measure death rates at ages long after most people finish their education.

\footnotetext{
${ }^{45}$ For example, suppose there are 2,000 people that were born in Georgia that are alive in 1980, and 1,800 people that were born in Georgia that were alive in 1990. If the census is a 1 in 20 sample, this would imply 100 people being sampled in 1980 and 90 people being sampled in 1990. These numbers correspond to a death rate of $10 \%$. However, if due to sampling error 101 people are sampled in 1990 (instead of 90), this implies a death rate of -1\%. This type of error, of either over-sampling or under-sampling is much more likely with smaller samples, which is the case for state-of-births with a small number of observations.

${ }^{46}$ There are 12 of these "small" population states with less than 20,000 observations in a state of birth and cohort.

${ }^{47}$ Positive mortality-schooling gradients indicate that higher education groups have higher death rates.

${ }^{4}$ Almond, Chay, \& Lee (2005) and Behrman and Rosenzweig (2004) have also examined this issue using withintwin variation, looking at short-run and long-run outcomes, respectively.
} 
There is also a minor issue with how I assign the quality variables. In the second part of the analysis where I construct mortality-schooling gradients, I regress the gradients on the quality variables for someone who went to school for 12 years, since I cannot assign quality by years of education attained. For example, to someone born in 1912 who only went to school for eight years, I should assign the quality variables from 1918 to 1926 and not 1918 to 1930 . This misassignment of school quality is only a problem if there were drastic changes in school quality for different states in a short period of time.

\section{Conclusion}

This paper provides evidence on the positive relationship between school quality and health, using mortality as the outcome of interest. In the estimations that looked at the direct relationship between school quality and death rates, improving the pupil teacher ratio and length of school term by one standard deviation decreases the death rate by about 1.5 percentage points. Furthermore, the length of school term and relative teacher wage are the most significant predictors of the mortality-schooling gradient. A one standard deviation improvement in quality is associated with an average 1.6 percentage point decrease in the death rate per year of schooling. Working with an average death rate in these cohorts of 12.38 percent, the 12.9 percent decrease is quite substantial.

Previous papers point to improvements in earnings and test scores as results of improved school quality. Under the assumptions outlined in the body of the paper, my results indicate that there are also positive outcomes related to health that have thus far been ignored. This suggests that the benefits of increased quality of education are greater than previously thought. By empirically estimating the effects of school quality on mortality my work has important 
implications for education policy. 


\section{Appendix: Robustness Checks}

While I run the main specification with four education categories, I can establish the mortality-schooling gradient in other forms. For instance, I can use different combinations of categories of years of schooling to either 1) have more observations establishing the gradient, or 2) fewer categories to reduce "jumping" between categories. Also, if the mortality returns to education differ by gender, the sample can be split that way as well.

In one of these other specifications, I obtain the gradient via three education categories rather than four. The categories of 12 years of education and 13 years of education or more are unchanged, while I combine those that got less than a high school education into one category. While the significance of the relative teacher wage is still evident, the length of school term is not precisely estimated, and the pupil-teacher ratio has the unexpected $\operatorname{sign}{ }^{49}$. One possibility for this unexpected result is that a crucial part of the mortality-schooling gradient that was previously explained by the quality variables is now merged into one. That is, school quality may play a crucial role in differential death rates at the lower end of the years of education distribution.

I obtain two more specifications by dividing the years of schooling into only two categories (instead of three and four) in two different ways. One approach is to examine the gradient between those with less than a high school education and those with at least a high school education. Another is to look at those with a high school education or less and those with more than a high school education. In general, these estimations are imprecise, although there are some significant results for the relative teacher wage, as there were in the main specifications.

\footnotetext{
${ }^{49}$ These results, as well as the results when I divide the years of schooling into two categories, are available upon request.
} 
Running the model by gender using four education categories makes the results less precise, but similar in sign to when the two are combined ${ }^{50}$. Fewer observations and therefore more imprecise measurements of death rates are most likely the cause for this.

In other work (which I do not report here), I use the NHANES to construct a gradient of total blood pressure (systolic blood pressure and diastolic blood pressure combined) on years of schooling. I then examine to what extent this gradient can be explained by the school quality measures outlined above. The results are very noisy, due mostly to: 1) 17 states being dropped due to an insufficient number of observations needed to construct meaningful averages of education and blood pressure, thus leaving the final regressions with 96 instead of 147 observations, and 2) even those states where I construct a gradient having too few observations to be reliable.

\footnotetext{
${ }^{50}$ These results are available upon request.
} 


\section{$\underline{\text { References }}$}

Almond, D., Chay, K. Y., \& Lee, D. S. (2005). The costs of low birth weight. Quarterly Journal of Economics, 120(3), 1031-1083.

Angrist J. D., \& Lavy, V. (1999). Using Maimonides' rule to estimate the effect of class size on scholastic achievement. The Quarterly Journal of Economics, 114(2), 533-575.

Arendt, J. N. (2005). Does education cause better health? A panel data analysis using school reforms for identification. Economics of Education Review, 24(2), 149-160.

Barsky, R. B., Juster, F. T., Kimball M. S., \& Shapiro M. D. (1997). Preference parameters and behavioral heterogeneity: An experimental approach in the health and retirement study. The Quarterly Journal of Economics, 112(2), In Memory of Amos Tversky (1937-1996), 537-579.

Bedard, K. (2003). School quality and the distribution of male earnings in Canada. Economics of Education Review, 22(4), 395-407.

Behrman, J. R., \& Rosenzweig, M. R. (2004). Returns to birthweight. Review of Economics and Statistics, 86(2), 586-601.

Berger, M. C., \& Leigh, J. P. (1989). Schooling, self-selection, and health. The Journal of Human Resources, 24( 3), 433-455.

Black, S. E. (1999). Do better schools matter? Parental evaluation of elementary education. The Quarterly Journal of Economics, 114( 2), 577-599.

Black, S. E., Devereux, P. J., \& Salvanes, K. G. (2007). From the cradle to the labor market? The effect of birth Weight on adult outcomes. Quarterly Journal of Economics, 122(1), 403439.

Card, D., \& Krueger, A. B. (1992). Does school quality matter? Returns to education and the characteristics of public schools in the United States. The Journal of Political Economy, 100( 1), $1-40$.

Card, D., \& Krueger, A. B. (1998). School resources and student outcomes. Annals of the American Academy of Political and Social Science, 559(1), The Changing Educational Quality of the Workforce, 39-53.

Cutler, D. M., \& Lleras-Muney, A. (2008). Education and health: Evaluating theories and evidence. In R. F. Schoeni, J. S. House, G. A. Kaplan, \& H. Pollack (Eds.) Making Americans Healthier: Social and Economic Policy as Health Policy (pp. 29-60). New York: Russell Sage Foundation. 
Dustmann, C., Rajah, N., \& van Soest, A. (2003). Class size, education, and wages. The Economic Journal, 113(485), F99-F120.

Fuchs, V. R. (1982). Time preference and health: An exploratory study. In V. Fuchs (ed.) Economic Aspects of Health (pp. 93-119). Chicago: University of Chicago Press.

Goldman, D., \& Lakdawalla, D. (2001). Understanding health disparities across education groups. NBER Working Paper No. 8328.

Goldman, D., \& Smith, J. P. (2005). Socioeconomic differences in the adoption of new medical technologies. American Economic Review Papers and Proceedings, 95(2), 234-237.

Goldman, D. P., \& Smith, J. P. (2002). Can patient self-management help explain the SES health gradient? Proceedings of the National Academy of Sciences, 99(16), 10929-10934.

Grabner, M. (2006). Education and obesity: Evidence from compulsory schooling laws. Mimeo, University of California, Davis.

Hanushek, E. A. (1996). School resources and student performance. In G. Burtless (Ed.). Does Money Matter: The Effect of School Resources on Student Achievement and Adult Success (pp. 43-73). Washington, D.C.: Brookings Institution Press.

Heckman, J., Layne-Farrar, A., \& Todd, P. (1996). Does measured school quality really matter? In G. Burtless (Ed.). Does Money Matter: The Effect of School Resources on Student Achievement and Adult Success (pp. 192-289). Washington, D.C.: Brookings Institution Press.

Heron, M. P., Hoyert, D. L., Xu, J., Scott, C., \& Tejada-Vera, B. (2008). National Vital Statistics Reports, 56(16)Table A.

URL: http://www.cdc.gov/nchs/data/nvsr/nvsr56/nvsr56_16.pdf (last accessed 3/18/2010)

Hoxby, C. (2000). The effects of class size on student achievement: New evidence from population variation. The Quarterly Journal of Economics, 115(4), 1239-1285.

Kolata, G. (2007). A surprising secret to a long life: Stay in school," New York Times, Jan. 3, A.1.

Krueger, A. B. (1999). Experimental estimates of the education production function. The Quarterly Journal of Economics, 114(2), 497-532.

Lleras-Muney, A. (2005). The relationship between education and adult mortality in the United States. The Review of Economic Studies, 72(1), 189-221.

Lleras-Muney, A. (2006). Erratum: The relationship between education and adult mortality in the United States. The Review of Economic Studies, 73(3), 847. 
Lleras-Muney, A., \& Lichtenberg, F. R. (2002). The effect of education on medical technology adoption: Are the more educated more likely to use new drugs? NBER Working Paper No. 9185.

Mazumder, B. (2008). Does education improve health? A reexamination of the evidence from compulsory schooling laws. Economic Perspectives, 32(2), 2-16.

Miniño, A. M., Anderson, R. N., Fingerhut, L. A., Boudreault, M. A., \& Warner, M. (2006). National Vital Statistics Report, 54(10), Table A. URL: http://www.cdc.gov/nchs/data/nvsr/nvsr54/nvsr54_10.pdf (last accessed 3/18/2010)

Oreopoulos, P. (2007). Do dropouts drop out too soon? Wealth, health, and happiness from compulsory schooling. Journal of Public Economics, 91(11-12), 2213-2229.

Pritchett, L., \& Filmer, D. (1999). What education production functions really show: A positive theory of educational expenditures. Economics of Education Review, 18(2), 223-239.

Ross, C. E., \& Wu, C. (1995). The links between education and health. American Sociological Review, 60(5), 719-745.

Ruggles, S., Sobek, M., Alexander T., Fitch, C. A., Goeken, R. , Hall, P. K., King, M., \& Ronnander, C. (2004). Integrated Public Use Microdata Series: Version 3.0. Minneapolis, MN: Minnesota Population Center.

Silles, M. A. (2009). The causal effect of education on health: Evidence from the UK. Economics of Education Review, 28 (1), 122-128.

Smith, J. P. (2004). Unraveling the SES-health connection. The Institute for Fiscal Studies, WP04/02.

Smith, J. P. (2007). Diabetes and the rise of the SES health gradient. NBER Working Paper No. 12905.

Stacey, N. (1998). Social benefits of education. Annals of the American Academy of Political and Social Science, 559(1), 54-63.

U.S. Census Bureau, Population Division, Interim State Population Projections, 2005. Internet Release Date: April 21, 2005.

URL: www.census.gov/population/projections/MethTab2.xls (last accessed 3/18/2010)

U.S. Census Bureau of the Census, Statistical Abstract of the United States, Washington, D.C., (various years). 
U.S. Department of Health and Human Services, Centers for Medicare and Medicaid Services, National Health Expenditures Data, "NHE Web Tables", Table 1.

URL: http://www.cms.hhs.gov/NationalHealthExpendData/downloads/tables.pdf (last accessed $3 / 18 / 2010)$

U.S. Office of Education. Biennial Survey of Education. Washington, D.C.: G.P.O. (various years).

Zuckerbrod, N., \& Trujillo M. (2007). Longer school day under review across nation. The Rock Hill Herald (via Associated Press). Feb. 26, Page 5B. 


\section{$\underline{\underline{\text { Figures }}}$}

\section{Convergence of education quality variables over time}

Figure 1

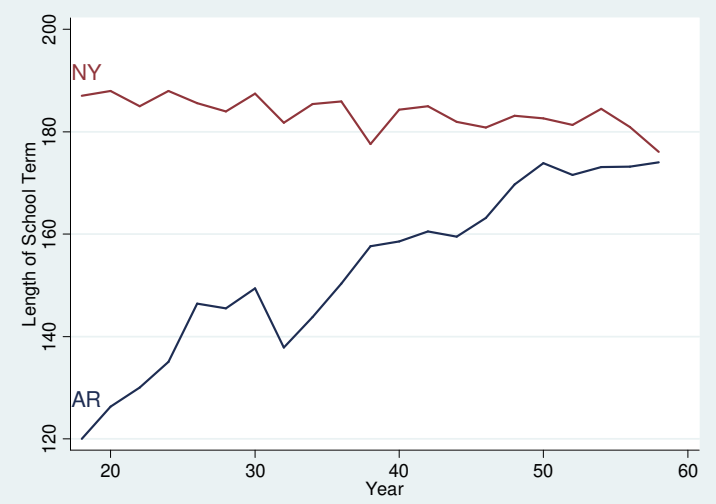

Figure 2

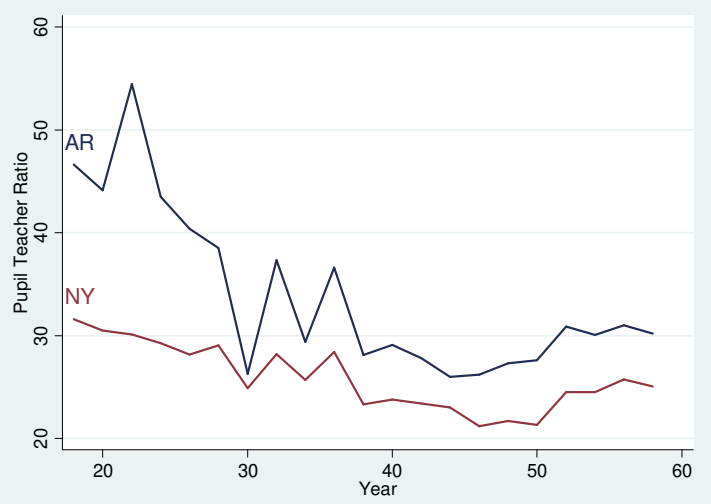

Figure 3

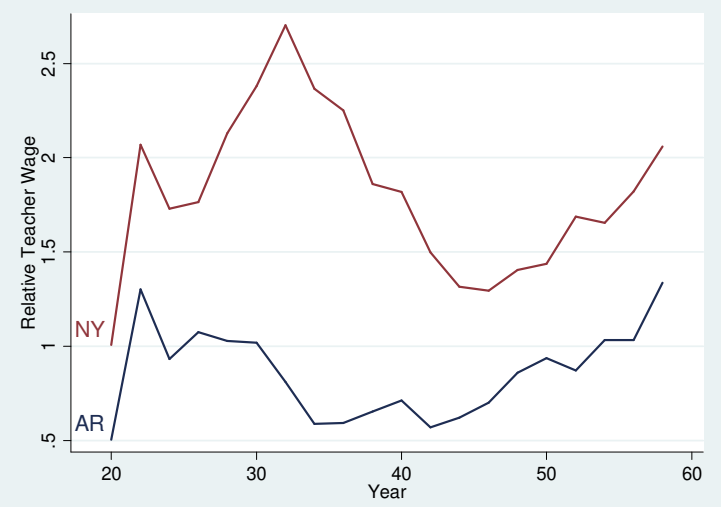

Note: Graphs above show the converging school quality over time between a representative high-quality education state (New York), and a representative low-quality education state (Arkansas)

\section{How $\beta s$ are calculated (equation (2))}

Figure 4

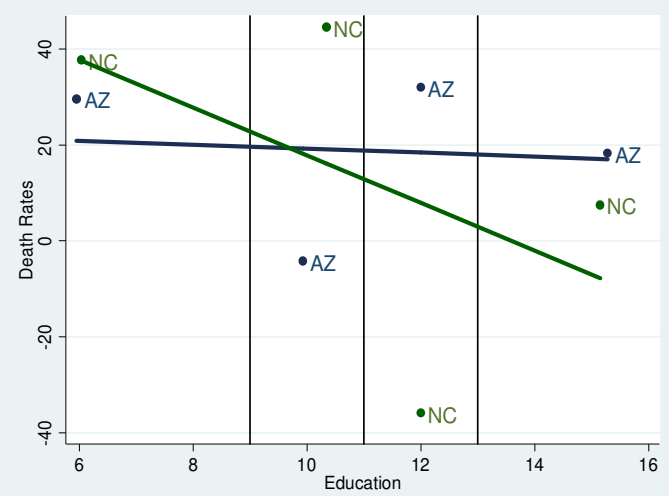

Note: Each point represents the average education and death rate for people that fall within that education group. 
Correlations between school quality measures and death rates; 1912-1921 birth cohort and 1990-2000 census pair

Pupil-Teacher Ratio and Death Rates

Figure 5

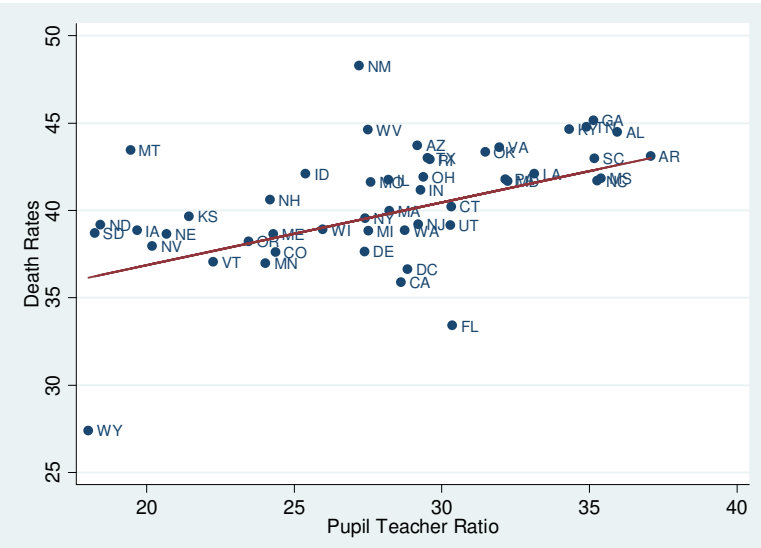

Length of School Term and Death Rates

Figure 6

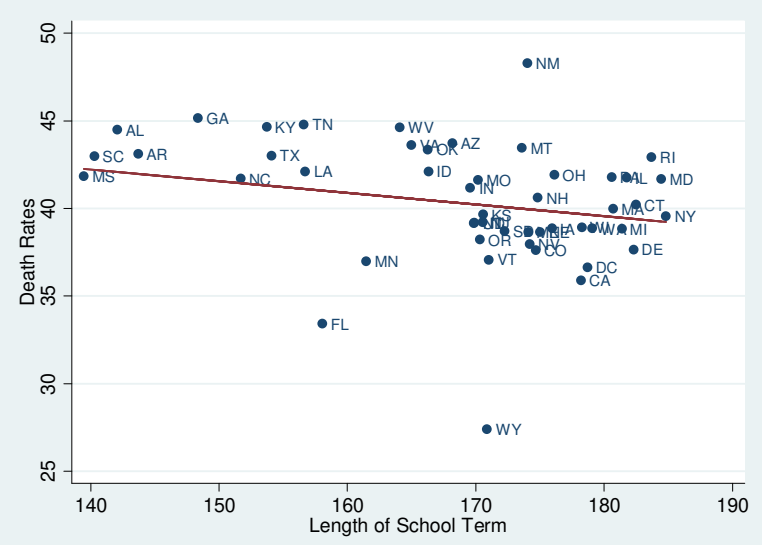

Relative Teacher Wage and Death Rates

Figure 7

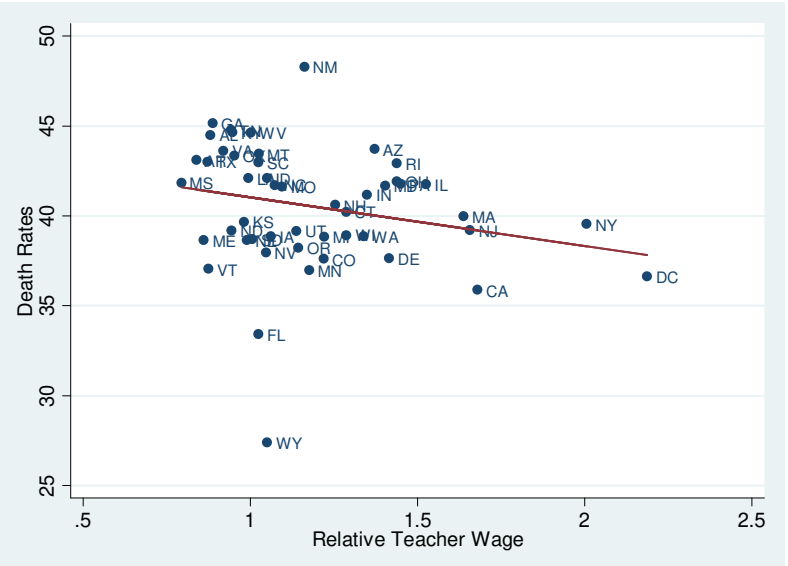

Note: Relationship between school quality variables and death rates. Lines weighted by population in state of birth. 


\section{$\underline{\underline{T a b l e s}}$}

\section{Table 1}

Summary Statistics

\begin{tabular}{|c|c|c|c|}
\hline \multirow[b]{2}{*}{ Variable } & \multicolumn{3}{|c|}{ Cohort } \\
\hline & Birth Years 1912-1921 & Birth Years 1922-1931 & Birth Years 1932-1941 \\
\hline \multicolumn{4}{|l|}{ School Quality: } \\
\hline Pupil-Teacher Ratio & 27.93 & 25.39 & 24.77 \\
\hline Length of School Term & 168.79 & 172.82 & 177.50 \\
\hline Relative Teacher Wage & 1.182 & 1.109 & 1.144 \\
\hline Death Rates (1970-1980) & 4.65 & -2.42 & -2.88 \\
\hline Education (1970) & 10.13 & 10.97 & 11.54 \\
\hline Income (1970) & 10222 & 11326 & 10551 \\
\hline Death Rates (1980-1990) & 23.92 & 11.20 & 4.45 \\
\hline Education (1980) & 11.04 & 11.77 & 12.46 \\
\hline Income (1980) & 5224 & 10165 & 11600 \\
\hline Death Rates (1990-2000) & 40.48 & 21.31 & 10.46 \\
\hline Education (1990) & 11.02 & 11.74 & 12.51 \\
\hline Income (1990) & 1191 & 5572 & 12400 \\
\hline Education Gradient (1970-1980) & -1.37 & -3.04 & -4.41 \\
\hline Education Gradient (1980-1990) & -3.30 & -3.55 & -4.68 \\
\hline Education Gradient (1990-2000) & -2.17 & -2.12 & -0.97 \\
\hline \multicolumn{4}{|c|}{ Mean Death Rates (by education category) } \\
\hline $0-8$ years of education & 30.51 & 21.05 & 18.25 \\
\hline $9-11$ years of education & 25.34 & 14.63 & 11.97 \\
\hline 12 years of education & 22.27 & 11.79 & 9.14 \\
\hline $13+$ years of education & 10.97 & -4.02 & -12.77 \\
\hline All values are state means; $n=49$ & & & \\
\hline
\end{tabular}


Table 2: Direct Relationship Between School Quality and Death Rates Dependent Variable: Death Rates

\begin{tabular}{|c|c|c|c|c|c|c|c|c|}
\hline Independent Variable & $(1)$ & $(2)$ & (3) & (4) & $(5)$ & $(6)$ & $(7)$ & $(8)$ \\
\hline Pupil Teacher Ratio & $\begin{array}{c}0.331 \\
(0.133)^{* *}\end{array}$ & & & $\begin{array}{c}0.218 \\
(0.177)\end{array}$ & $\begin{array}{c}0.188 \\
(0.127)\end{array}$ & & & $\begin{array}{l}-0.099 \\
(0.149)\end{array}$ \\
\hline Length of Term & & $\begin{array}{c}-0.086 \\
(0.031)^{* * *}\end{array}$ & & $\begin{array}{c}-0.080 \\
(0.038)^{* *}\end{array}$ & & $\begin{array}{c}-0.124 \\
(0.028)^{* * *}\end{array}$ & & $\begin{array}{c}-0.171 \\
(0.050)^{* * *}\end{array}$ \\
\hline Relative Teacher Wage & & & $\begin{array}{c}1.189 \\
(2.220)\end{array}$ & $\begin{array}{c}4.353 \\
(1.968)^{* *}\end{array}$ & & & $\begin{array}{l}-0.997 \\
(1.818)\end{array}$ & $\begin{array}{c}4.226 \\
(2.389)^{*}\end{array}$ \\
\hline Income (1000s) & & & & & $\begin{array}{c}-0.952 \\
(0.067)^{* * *}\end{array}$ & $\begin{array}{c}-0.953 \\
(0.066)^{* * *}\end{array}$ & $\begin{array}{c}-0.948 \\
(0.068)^{* * *}\end{array}$ & $\begin{array}{c}-0.948 \\
(0.067)^{* * *}\end{array}$ \\
\hline Metropolitan (\%) & & & & & $\begin{array}{c}7.258 \\
(5.956)\end{array}$ & $\begin{array}{c}7.346 \\
(5.947)\end{array}$ & $\begin{array}{c}7.281 \\
(5.949)\end{array}$ & $\begin{array}{c}7.313 \\
(5.965)\end{array}$ \\
\hline Age & & & & & $\begin{array}{c}-11.092 \\
(4.125)^{* * *}\end{array}$ & $\begin{array}{c}-11.479 \\
(4.165)^{* * *}\end{array}$ & $\begin{array}{c}-11.518 \\
(4.172)^{* * *}\end{array}$ & $\begin{array}{c}-11.874 \\
(4.240)^{* * *}\end{array}$ \\
\hline p-value of qual. vars. & & & & 0.0006 & & & & 0.0013 \\
\hline Cohort Effects & Yes & Yes & Yes & Yes & Yes & Yes & Yes & Yes \\
\hline State Effects & Yes & Yes & Yes & Yes & Yes & Yes & Yes & Yes \\
\hline Group Effects & Yes & Yes & Yes & Yes & Yes & Yes & Yes & Yes \\
\hline Observations & 441 & 441 & 441 & 441 & 441 & 441 & 441 & 441 \\
\hline $\mathrm{R}^{2}$ & 0.827 & 0.826 & 0.826 & 0.827 & 0.899 & 0.900 & 0.899 & 0.900 \\
\hline
\end{tabular}

Note - Observations are averaged over states, three ten year birth cohorts, and three census pairings (1970-1980, 1980-1990, and 1990-2000).

Standard errors clustered on state in parentheses; Death rates measured in percentages; *significant at $10 \%$; ** 5\%; *** $1 \%$ 
Table 3: Direct Ralationship Between School Quality and Death Rates

Dependent Variable: Death Rates

\begin{tabular}{|c|c|c|c|c|c|c|c|c|c|}
\hline Independent Variable & (1) & (2) & (3) & (4) & (5) & (6) & (7) & (8) & (9) \\
\hline \multirow{2}{*}{ Education } & -2.537 & -2.113 & -2.295 & -2.785 & -2.506 & 1.097 & 1.136 & 0.635 & 0.952 \\
\hline & $(2.419)$ & $(2.669)$ & $(2.501)$ & $(2.510)$ & (2.679) & (1.783) & (1.487) & (1.633) & (1.838) \\
\hline \multirow{2}{*}{ Pupil Teacher Ratio } & & 0.188 & & & 0.032 & 0.260 & & & -0.031 \\
\hline & & $(0.199)$ & & & $(0.203)$ & $(0.186)$ & & & $(0.233)$ \\
\hline \multirow{2}{*}{ Length of Term } & & & -0.058 & & -0.097 & & -0.138 & & -0.165 \\
\hline & & & $(0.044)$ & & $(0.038)^{* *}$ & & $(0.030)^{* * *}$ & & $(0.058)^{* * *}$ \\
\hline \multirow{2}{*}{ Relative Teacher Wage } & & & & 3.620 & 6.579 & & & -1.548 & 3.387 \\
\hline & & & & $(2.696)$ & $(2.983)^{* *}$ & & & $(2.121)$ & $(3.230)$ \\
\hline \multirow{2}{*}{ Income (1000s) } & & & & & & -0.958 & -0.959 & -0.952 & -0.955 \\
\hline & & & & & & $(0.074)^{* * *}$ & $(0.071)^{* * *}$ & $(0.073)^{* * *}$ & $(0.075)^{* * *}$ \\
\hline \multirow{2}{*}{ Metropolitan (\%) } & & & & & & 7.278 & 7.378 & 7.303 & 7.339 \\
\hline & & & & & & $(5.935)$ & $(5.916)$ & $(5.915)$ & -5.931 \\
\hline \multirow{2}{*}{ Age } & & & & & & -11.276 & -11.846 & -11.705 & -11.988 \\
\hline & & & & & & $(3.975)^{* * *}$ & $(3.936)^{* * *}$ & $(3.941)^{* * * *}$ & $(4.139)^{* * *}$ \\
\hline p-value of qual. vars. & & & & & 0.0243 & & & & 0.0006 \\
\hline Cohort Effects & Yes & Yes & Yes & Yes & Yes & Yes & Yes & Yes & Yes \\
\hline State Effects & Yes & Yes & Yes & Yes & Yes & Yes & Yes & Yes & Yes \\
\hline Group Effects & Yes & Yes & Yes & Yes & Yes & Yes & Yes & Yes & Yes \\
\hline Observations & 441 & 441 & 441 & 441 & 441 & 441 & 441 & 441 & 441 \\
\hline $\mathrm{R}^{2}$ & 0.827 & 0.827 & 0.827 & 0.827 & 0.828 & 0.899 & 0.900 & 0.899 & 0.900 \\
\hline
\end{tabular}

Note - Observations are averaged over states, three ten year birth cohorts, and three census pairings (1970-1980, 1980-1990, and 1990-2000)

Standard errors clustered on state in parentheses; Death rates measured in percentages; *significant at $10 \%$; ** 5\%; *** $1 \%$ 
Table 4: Relationship Between School Quality and Mortality-Schooling Gradient Dependent Variable: Education Gradient by State/Cohort

\begin{tabular}{|c|c|c|c|c|c|c|c|c|}
\hline \multirow[b]{2}{*}{ Independent Variable } & \multicolumn{4}{|c|}{ Unrestricted Sample } & \multicolumn{4}{|c|}{ Restricted Sample } \\
\hline & (1) & (2) & (3) & (4) & (5) & (6) & (7) & (8) \\
\hline \multirow{2}{*}{ Pupil Teacher Ratio } & 0.018 & & & 0.013 & 0.034 & & & 0.024 \\
\hline & $(0.018)$ & & & $(0.018)$ & $(0.016)^{* *}$ & & & $(0.018)$ \\
\hline \multirow{2}{*}{ Length } & & -0.009 & & 0.001 & & -0.011 & & -0.002 \\
\hline & & $(0.006)$ & & $(0.008)$ & & $(0.006)^{*}$ & & $(0.008)$ \\
\hline \multirow{2}{*}{ Relative Teacher Wage } & & & -0.772 & -0.768 & & & -0.692 & -0.613 \\
\hline & & & $(0.235)^{* * *}$ & $(0.276)^{* * *}$ & & & $(0.239) * * *$ & $(0.291)^{* *}$ \\
\hline \multirow{2}{*}{ Income (1000s) } & -0.009 & -0.008 & -0.003 & -0.004 & -0.008 & -0.006 & -0.003 & -0.004 \\
\hline & $(0.003)^{* * *}$ & $(0.003)^{* * *}$ & $(0.002)$ & $(0.003)$ & $(0.003)^{* * *}$ & $(0.002)^{* * *}$ & $(0.002)$ & $(0.003)$ \\
\hline \multirow{2}{*}{ Metropolitan (\%) } & -3.624 & -3.549 & -3.492 & -3.496 & -4.024 & -3.917 & -3.885 & -3.888 \\
\hline & $(1.134)^{* * *}$ & $(1.116)^{* * *}$ & $(1.105)^{* * *}$ & $(1.117)^{* * *}$ & $(1.209)^{* * *}$ & $(1.187)^{* * *}$ & $(1.178)^{* * *}$ & $(1.194)^{* * *}$ \\
\hline p-value of qual. vars. & & & & 0.0147 & & & & 0.0185 \\
\hline Cohort Effects & Yes & Yes & Yes & Yes & Yes & Yes & Yes & Yes \\
\hline State Effects & Yes & Yes & Yes & Yes & Yes & Yes & Yes & Yes \\
\hline Group Effects & Yes & Yes & Yes & Yes & Yes & Yes & Yes & Yes \\
\hline Observations & 441 & 441 & 441 & 441 & 333 & 333 & 333 & 333 \\
\hline $\mathrm{R}^{2}$ & 0.612 & 0.612 & 0.613 & 0.613 & 0.629 & 0.629 & 0.63 & 0.63 \\
\hline
\end{tabular}

Note - Observations based on three cohorts per census group (1970-1980; 1980-1990; 1990-2000) for 49 states Standard errors clustered on state in parentheses; *significant at $10 \%$; ** 5\%; *** $1 \%$.

Restricted sample includes 37 states with at least 20,000 obs per state-census pair-cohort 
Table 5: Relationship Between School Quality and Mortality-Schooling Gradient (including interacted fixed effects)

Dependent Variable: Education Gradient by State/Cohort

\begin{tabular}{|c|c|c|c|c|c|c|c|c|}
\hline \multirow[b]{2}{*}{ Independent Variable } & \multicolumn{4}{|c|}{ Unrestricted Sample } & \multicolumn{4}{|c|}{ Restricted Sample } \\
\hline & (1) & (2) & (3) & (4) & (5) & (6) & (7) & (8) \\
\hline \multirow{2}{*}{ Pupil Teacher Ratio } & 0.017 & & & 0.021 & 0.035 & & & 0.041 \\
\hline & $(0.020)$ & & & $(0.021)$ & $(0.018)^{*}$ & & & $(0.022)^{*}$ \\
\hline \multirow{2}{*}{ Length } & & -0.004 & & 0.005 & & -0.005 & & 0.005 \\
\hline & & $(0.008)$ & & $(0.010)$ & & $(0.008)$ & & $(0.010)$ \\
\hline \multirow{2}{*}{ Relative Teacher Wage } & & & -0.611 & -0.663 & & & -0.412 & -0.407 \\
\hline & & & $(0.324)^{*}$ & $(0.354) *$ & & & $(0.340)$ & $(0.393)$ \\
\hline \multirow{2}{*}{ Income (1000s) } & -0.007 & -0.006 & -0.003 & -0.003 & -0.006 & -0.004 & -0.002 & -0.004 \\
\hline & $(0.003)^{* *}$ & $(0.003)^{* *}$ & $(0.003)$ & $(0.003)$ & $(0.002)^{* *}$ & $(0.002)^{* *}$ & $(0.003)$ & $(0.003)$ \\
\hline \multirow{2}{*}{ Metropolitan (\%) } & -6.121 & -5.469 & -4.040 & -4.655 & -8.075 & -7.001 & -6.240 & -7.371 \\
\hline & $(2.007)^{* * *}$ & $(2.209)^{* *}$ & $(2.174)^{*}$ & $(2.483)^{*}$ & $(1.727)^{* * *}$ & $(2.056)^{* * *}$ & $(2.068)^{* * *}$ & $(2.497)^{* * *}$ \\
\hline p-value of qual. vars. & & & & 0.1705 & & & & 0.0916 \\
\hline Observations & 441 & 441 & 441 & 441 & 333 & 333 & 333 & 333 \\
\hline $\mathrm{R}^{2}$ & 0.923 & 0.923 & 0.924 & 0.924 & 0.937 & 0.936 & 0.936 & 0.937 \\
\hline
\end{tabular}

Note - All regressions include cohort, state, group, cohort*group, and state*group fixed effects

Observations based on three cohorts per census group (1970-1980; 1980-1990; 1990-2000) for 49 states

Standard errors clustered on state in parentheses; *significant at $10 \%$; ** 5\%; *** $1 \%$

Restricted sample includes 37 states with at least 20,000 obs per state-census pair-cohort 


\section{Table 6: Relationship Between School Quality and Mortality-Schooling Gradient (extended quality variables)}

Dependent Variable: Education Gradient by State/Cohort

\begin{tabular}{|c|c|c|c|c|c|c|c|c|c|c|c|c|}
\hline & & & Unrestric & ed Sam & & & & & Restricte & d Sample & & \\
\hline Independent Variable & $(1)$ & $(2)$ & (3) & (4) & $(5)$ & (6) & (7) & $(8)$ & (9) & $(10)$ & $(11)$ & $(12)$ \\
\hline Punil Teacher Ratio & 0.018 & & & & & 0.017 & 0.034 & & & & & 0.022 \\
\hline 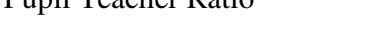 & $(0.018)$ & & & & & $(0.018)$ & $(0.016)^{* *}$ & & & & & $(0.018)$ \\
\hline Jenoth of Term & & -0.009 & & & & 0.001 & & -0.011 & & & & 0.000 \\
\hline LCन & & $(0.006)$ & & & & $(0.007)$ & & $(0.006)^{*}$ & & & & $(0.007)$ \\
\hline Relative Teacher Wage & & & -0.772 & & & -0.569 & & & -0.692 & & & -0.425 \\
\hline & & & $(0.235)^{* * *}$ & & & $(0.247)^{* *}$ & & & $(0.239) * * *$ & & & $(0.263)$ \\
\hline Students ner School (1000s) & & & & 1.581 & & 0.600 & & & & 3.057 & & 1.843 \\
\hline 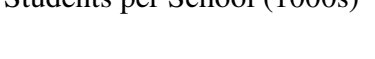 & & & & (1.179) & & $(1.036)$ & & & & $(1.058)^{* * *}$ & & $(0.883)^{* *}$ \\
\hline Percent 1-room Schools & & & & & -1.172 & -0.742 & & & & & -1.101 & -0.498 \\
\hline & & & & & $(0.509)^{* *}$ & $(0.431)^{*}$ & & & & & $(0.498)^{* *}$ & $(0.342)$ \\
\hline p-value of qual. vars. & & & & & & 0.0018 & & & & & & 0.0011 \\
\hline Cohort Effects & Yes & Yes & Yes & Yes & Yes & Yes & Yes & Yes & Yes & Yes & Yes & Yes \\
\hline State Effects & Yes & Yes & Yes & Yes & Yes & Yes & Yes & Yes & Yes & Yes & Yes & Yes \\
\hline Group Effects & Yes & Yes & Yes & Yes & Yes & Yes & Yes & Yes & Yes & Yes & Yes & Yes \\
\hline Observations & 441 & 441 & 441 & 441 & 441 & 441 & 333 & 333 & 333 & 333 & 333 & 333 \\
\hline $\mathrm{R}^{2}$ & 0.612 & 0.612 & 0.613 & 0.612 & 0.613 & 0.614 & 0.629 & 0.629 & 0.630 & 0.630 & 0.630 & 0.631 \\
\hline
\end{tabular}

Note - All equations include controls for percent in Metro area and Income; Standard errors clustered on state in parentheses; *significant at $10 \%$; $* * 5 \%$; *** $1 \%$

Observations based on three cohorts per census group (1970-1980; 1980-1990; 1990-2000) for 49 states

Restricted sample includes 37 states with at least 20,000 obs per state-census pair-cohort 